\title{
Review of fatigue crack growth under non-proportional loading
}

\author{
M. Vormwald ${ }^{1}$ and P. Zerres $^{2}$ \\ 1 Material Mechanics Group, Technische Universität Darmstadt, Petersenstraße 12, \\ 64287 Darmstadt, Germany, e-mail: vormwald@wm.tu-darmstadt.de \\ 2 ELAN-AUSY GmbH, Channel 2, Harburger Schloßstraße 24, 21079 Hamburg, \\ Germany, e-mail: patrick.zerres@elan-ausy.com
}

\begin{abstract}
Cyclic non-proportional loading is common experimental practise for investigations of large structures like vehicles. Numerical analysis of local nonproportional loading conditions is also a well established field of research and application. However, theoretical and practical support is rare for evaluating the growth of fatigue cracks under non-proportional cyclic loading conditions. At least seven influence factors - most of them not yet throroughly understood - are listed and discussed in the paper: the mode-mixity, the material's influence including its anisotropy if existant, the degree of cyclic plastic deformation and its direction ahead of the crack tip, the crack closure phenomenon, the related mean stress effect, the component's geometry in general and especially the variable mode-mixity along a crack front. Two crack propagation mechanisms must be considered: The tensile stress dominated, mode II minimising mechanism and the shear stess dominated mechanism. Transition mode-mixities are observed. Some successful explanations of experimental findings have been published, however, a generally accepted and validated formulation of a crack driving force parameter is out of sight.
\end{abstract}

\section{INTRODUCTION}

Most of the engineering structures and components are subjected to fatigue load conditions, which are a combination of various load sequences originating from different sources. Only in rare cases, a correlation of these load sequences may be observed. For ground vehicles, for example, the excitation provided by the roadway surface is uncorrelated with load sequences from manoeuvring, be it curving or acceleration and braking. After an onset of fatigue damage - for metallic materials this generally means the initiation of a fatigue crack - the crack is cyclically loaded in a way such that at the crack front non-proportional mixed-mode situations will exist.

In experimental investigations of the fatigue strength of such structures, it is common state of the art to reproduce the action of varios load sequences in their realistic interconnection in a laboratory. Chassis suspension test systems, for example, with 
twelve or more actuators simultaneously loading the structure is a common sight in vehicle test laboratories.

In numerical fatigue life assessments, methods for dealing with the initiation of fatigue cracks are available even for the complicated non-proportional cases of combined cyclic loading. The accuracy of the fatigue life estimates obtained by applying these methods and the associated software tools is still under thourough investigation. Nevertheless, the engineers responsible for the fatigue strength of the structures are supported by these helpful numerical tools. The theoretical and practical support immediately stops as soon as the growth of fatigue cracks under nonproportional cyclic loading conditions is a matter of concern. A great discrepancy exists between experimental and numerical feasibilities of performing a proof of structural durability.

The topic of non-proportional mixed-mode fatigue crack growth has become a field of scientific interest. The intention of this paper is to provide a collection of references to already investigated cases, the experimental observations and the analytical and numerical models developed therein.

\section{MIXED-MODE FRACTURE CRITERIA}

An early hypothesis for mixed-mode fracture was published by Erdogan and Sih [1]. Their maximum tangential stress criterion postulates that a mixed-mode loaded crack extends in the direction perpendicular to the maximum tangential stress ahead of the crack tip. The stress involved is usually calculated for linear elastic conditions and only the near the crack tip asymptotic, singular stress field is exploited. Shih [2], however, extended the maximum tangential stress criterion to elastic-plastic analysis for strain hardening material.

Sih [3] further proposed the strain energy density criterion according to which crack extension in the direction of the minimum strain energy density is assumed. Another energy-based approach was developed by Hussain et al. [4] who made the maximum energy release rate of a kinked crack responsible for fracture propagation. All of the hypotheses listed so far predict very similar directions of a growing crack under mixedmode I and II conditions. In the case that any of the aforementioned hypotheses is applied for fatigue crack growth analysis, the crack path is predicted such that the mode II loading at the crack tip is minimised.

A completely different path is obtained by the maximum shear stress criterion [5,6]. This criterion is especially useful in some cases when a crack subjected to mixed-mode I and II loading may remain or turn to propagate in a direction collinear with the plane of the maximum shear stress rather than the plane plane perpendicular to the maximum normal stress. Such a fatigue crack growth behaviour is observed, for example, during stage I of microstructurally short cracks as well as under enforced severe cyclic plastic deformation of notched axis-symmetric shafts under torsion. 
This initial list of most relevant mixed-mode fracture criteria is concluded with reference to extensive literature surveys of mixed-mode fatigue crack growth under proportional $[7,8,9]$ and non-proportional loading [10].

\section{OBSERVATIONS ON FATIGUE CRACKS GROWING UNDER NON- PROPORTIONAL LOADING}

Superimposing non-proportional mixed-mode conditions may be performed in innumerably different ways. In academic studies on the subject the available test rig is the limiting feature for the choice of non-proportional load sequences. Having only a uniaxial testing machine at hand, all what can be achieved is to change the crack tip loading mode (or the mode-mixity) abruptly by changing the specimens' fixing conditions. Investigations on mode I pre-cracked specimens which are sujected to a mode-mixity, $\tan \Phi=\Delta K_{\mathrm{II}} / \Delta K_{\mathrm{I}}$, different from zero may be seen as being investigations on non-proportional mixed-mode loading concerning the early growth after the mode-mixity change.

\section{Abrupt change of the mode-mixity}

The crack growth rate for the non-proportional first cycle after a mode-mixity change is experimentally inaccessible. The investigations focus on the crack deflection angle from the direction of the pre-crack grown under pure mode I. Since the early investigation of Iida and Kobayashi [11] the majority of experimental results $[7,8]$ show a crack turning or kinking towards a path minimising $\Delta K_{\mathrm{II}}$ which may be well described by the maximum tensile stress criterion. However, Roberts and Kibler [12] found cases for which the maximum tensile stress criterion was not valid. For high mode-mixities coplanar (with the original Mode I pre-crack) fatigue crack growth was observed. In descriptions of this observations, the maximum shear stress criterion must be called. Besides the mode-mixity, this behaviour seems to be dependent on the material under investigation. No clear classification is available today with respect to which materials show preferred obedience to a mixed-mode criterion deviating from the popular maximum tensile stress criterion and its close relatives, strain energy density and energy release rate criterion. A third factor influencing the fatigue crack growth behaviour must be emphasised: The co-planar, nearly maximum shear stress driven fatigue crack growth behaviour is observed preferrably for higher stress intensity factor ranges. At the same time, this means that larger and more extended cyclic plastic deformations occur in the vicinity of the crack tip. Plastic deformations in metals - when observed on the microscopic scale - are dislocation motions in planes with high shear stresses. It seems that these planes provide the opportunity for crack extension. Even under the conventional mode I fatigue crack growth situation, the micro mechanism of crack extension is explained by shear bands deviating from the mode I plane. Under mode I conditions two symmetric (to the mode I plane) shear systems are competing. After a deflection to the one side, the other, originally symmetric shear system's intensity increases and forces the crack tip to move back towards the symmetry plane. On the 
macro scale, this fatigue crack growth mechanism results in the rough fracture plane. Under mixed-mode conditions a symmetry-return mechanism may also appear after an initial kinking leading to the fatigue crack growth path described by the maximum tensile stress criterion. Eventually, at high mixed-mode stress intensity ranges, one shear plane remains dominating and the fatigue crack stays in this plane. For thes cases, even crack growth rate data can be aquired. A mixed mode stress intensity factor range $\Delta K_{\mathrm{MM}}$ was introduced replacing the conventional stress intensity factor range in a crack growth rate equation (see the overview in reference [10]) according to:

$$
\Delta K_{\mathrm{MM}}=\left(\Delta K_{\mathrm{I}}^{m}+q \cdot \Delta K_{\mathrm{II}}^{m}\right)^{1 / m}
$$

Values of $m=2$ together with $q=2$ were suggested as well as $m=4$ together with $q=4$ or $q=8$, or all of the parameters adjusted to experimental evidence [8].

In some cases, delayed deflection after a short distance of co-planar, shear mode driven propagation was observed, see for example Gao et al. [13]. Opposite (or in addition) to what was said to the data from reference [12], the co-planar growth was observed in the near threshold region. In the discussion of the obtained results a fourth item with strong influence on the fatigue crack growth behaviour is outlined: The crack closure mechanism must be considered. Especially the roughness induced closure in high mode-mixity situation gives rise to a mode II crack tip shielding for low stress intensity ranges. Large plastic deformations in combination with wear at the fracture surface may - on the other hand - remove and crack closure associated with mode II. As it is the case in mode I fatigue crack growth, crack closure and mean stress effect are closely related phenomena and therefore all effects should be discussed against the background of the mean stress or stress ratio effect, $R=K_{\min } / K_{\max }$.

In a recent investigation by Highsmith [10] the abrupt change of mode-mixity was not only performed from pure mode I to proportional mode II and mode I loading. Highsmith used mode I pre-cracked thin-walled tube specimens with the pre-crack oriented perpendicular to the specimen axis. With a testing equipment able to apply cyclic tension and torsion independently of each other on the specimen, real longranging non-proportional load sequences can be applied. The material was the Nickelbased super alloy Inconel 718. It was tested at room temperature and the maximum stress intensity factors at the pre-crack front were in the order of 10 to $25 \mathrm{MPa}^{0.5}$. Positive stress ratios were applied, $R=0.1$ in most cases with some results also for $R=$ 0.6 . In his accompanying study on proportional tension-torsion loading, he discovered the transition from the maximum tensile stress dominated crack deflection to the nearly co-planar maximum shear stress dominated crack growth occuring at a mode-mixity of $44^{\circ}$. The situation of two competing criteria may be visualised in an interaction diagram according to Figure 1. 


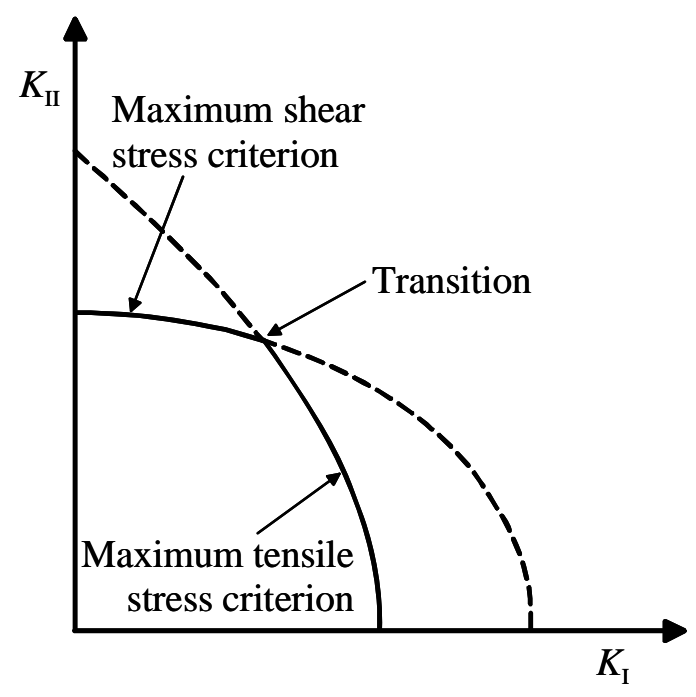

Figure 1. Schematic visualisation showing the competition of the maximum tensile and the maximum shear stress criterion.

In non-proportional mixed-mode loading the mode-mixity varies during a cycle. Highsmith presents his results in diagrams showing the deflection angle as a function of the mode-mixity. In Figure 2, the reproduction of some Highsmith's results, in especially the results for constant torsion and cyclic tension, show that none of the criteria mentioned so far is able to predict the correct deflection angle. This statement holds for both options, inserting the mode-mixity at the maximum load or for the ranges.

Highsmith also tested a few through-crack round specimens. The main difference between a thin-walled tube and the round shaft with a through-(pre-)crack is that the mode-mixity varies considerable along the crack front in the latter case. This issue inserts a sixth factor of influence on the non-proportional (but also on the proportional) mixed-mode fatigue crack growth: At the different positions along the crack front, the crack may obey to different criteria and therefore it may follow different deflection angles. The final fracture surface appears either strongly warped or it shows a step-like joining of cracks initially grown in different planes according to different criteria. Moreover, the out-of-plane constraints differ between the specimens in that the thinwalled tube creates a plane-stress situation and in the through-crack round specimen a plane-strain situation prevails. If the starter crack is cut in a direction which deviates from being perpendicular to the specimen axis, mode III non-proportional conditions may be investigated, too. Observations on this loading case are unaware to the present authors. 


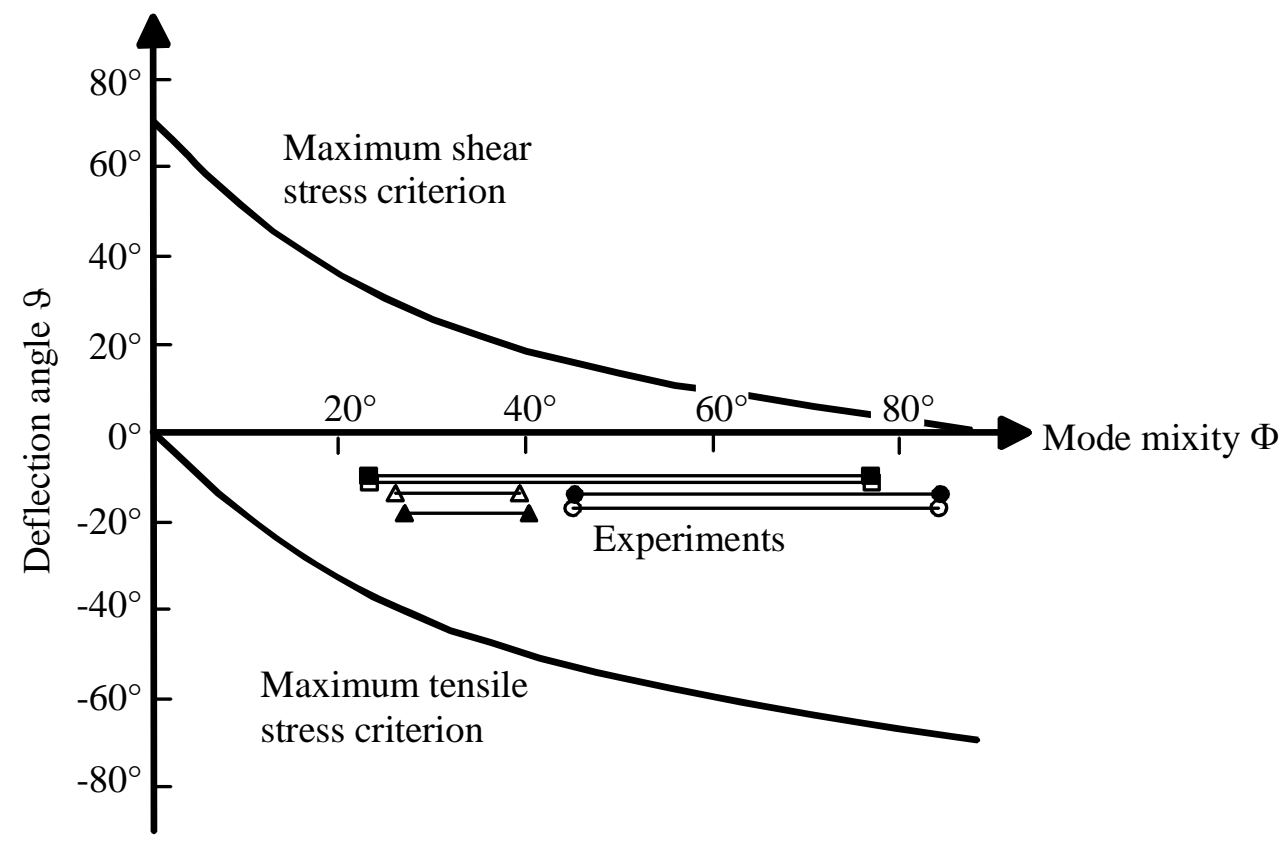

Figure 2. Crack deflection angles over the range of mode-mixity for constant torsion with superimposed cyclic tension after Highsmith [10].

Highsmith concludes there is no single formulation at hand to predict crack direction for all cases. A best-practise approach is proposed which is based on the stress intensity factors at an infinitesimally small kink crack's tip, $k_{1}$ and $k_{2}$.

$$
\begin{aligned}
& k_{1}=\cos \frac{\vartheta}{2}\left(K_{\mathrm{I}} \cos ^{2} \frac{\vartheta}{2}-\frac{3}{2} K_{\mathrm{II}} \sin \vartheta\right) \\
& k_{2}=\frac{1}{2} \cos \frac{\vartheta}{2}\left(K_{\mathrm{I}} \sin \vartheta+K_{\mathrm{II}}(3 \cos \vartheta-1)\right)
\end{aligned}
$$

In the Eqs. (2) and (3), $\vartheta$ is the kink angle. Since crack deflection angles fall between the angles of maximum kink tip stress intensity factor, $k_{i \text {,max }}$, and the maximum kink tip stress intensity factor range, $\Delta k_{\mathrm{i}}$, a crack driving force combining the influence of both was suggested:

$$
\Delta \bar{k}_{i}=\Delta k_{i}^{w} \cdot k_{i, \max }^{1-w}
$$

A fitting parameter, $w$, appears in Eq. (4) which is allowed to take different values for the two cases, $i=1$ (tensile stress dominated), and $i=2$ (shear stress dominated). A transition criterion similar to what is shown in Fig. 1 completes the approach.

Highsmith formulated his concept against the background of his overview on published results. The reference to two more summary papers by Liu [14] and Bold [15] 
is given here, both focussing on rolling contact fatigue which is a special type of nonproportional mixed mode loading. Some of these papers are discussed in a later paragraph; the others are referenced here for an attempt for - however, unreachable completeness [16-26]. Highsmith did not intend to compare crack growth rates when applying Eq. (4) in connection with a crack growth law for pure-mode loading. He only restricted his work to the description of deflection angles which, however, is an important pre-requisite for any fatigue crack growth modeling. In the following amendments to Highsmith's overview are listed.

\section{Effect of interposed mode II load cycles on mode I fatigue cracks}

It is well known that mode I overloading leads to a crack retardation or arrest $[27,28]$ under pure mode I loading. Investigating the effect of mode II overloads - as a special case of non-proportional loading - Nayeb-Hashemi and Taslim [29] found that in contrast to mode I overloads, mode II overloads give rise to short time crack growth acceleration with no retardation afterwards. In contrast to their observations, Gao and Upul [30], who applied ten overload cycles instead of only one, Srinivas and Vasudevan [31], Sander and Richard [32] as well as Dahlin and Olsson [33,34,35] observed an retardation of the mode I crack after the mode II overload, see Fig. 3. Based on the results shown in Fig. 3, Dahlin and Olsson [33,34,35] stated that there should be a certain threshold value for the mode II overload, below which no decrease of the subsequent mode I crack growth rate occurs. They found the crack closure due to the mode II displacement of the crack-surface roughness which causes mismatch between the upper and lower crack faces to be the main reason for the decrease in crack growth rate.

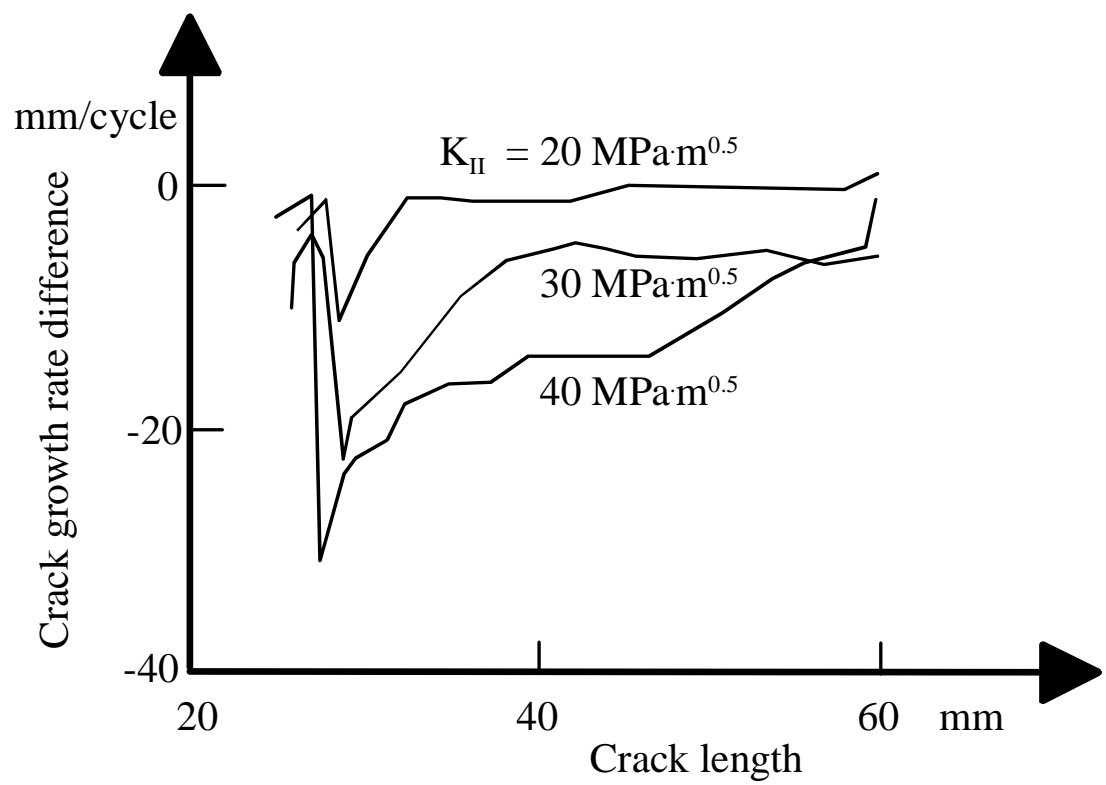

Figure 3. Change in mode I crack growth rate due to a single mode II load cycle of three different magnitudes $\left(\Delta \mathrm{K}_{\mathrm{I}}=20 \mathrm{MPam}^{0.5}, \mathrm{R}=0.1\right)$ after Dahlin [35]. 
Changing the overload from purely mode II to Mixed-mode, Sander and Richard [32] and Srinivas and Vasudevan [31] observed that, by fixing the size of the transient plastic zone, the crack growth rate retardation decreases with an increasing mode II portion.

Dahlin and Olsson [36] extendend their study to investigate not only the case of mode II overloads, but also periodic mode II cycles during mode I loading. They stated that $\Delta K_{\mathrm{I}}$, the $R$-ratio of the mode I loading, the magnitude of the mode II loadcycles and the frequency of the mode II cycles, i.e. the number of mode II loadcycles per mode I loadcycles, are the main parameters concerning the influence of the sequential mode II cycles on the crack growth behavior. They found two mechanisms resulting from the mode II loadcycles: mode II-induced crack closure, which results in a reduction of the crack propagation rate, and a mechanism that increases the growth rate temporary at every mode II load. For a crack with high mode I $R$-ratios, i.e. the crack is open during the whole mode I loadcycle, the decreasing effect of the mode II load on the crack growth rate vanishes. They also stated that the crack path deviation from the mode I crack path is only significant at high mode II frequencies, as shown in Fig. 4.



Figure 4. Crack path of a specimen under cyclic mode I loading with gradually increasing mode II frequency after Dahlin and Olssen [36].

As a limiting case of the aformentioned loading Doquet and Pommier [37] studied sequentially applied mode I and mode II load cycles in ferritic-pearlitic steel. They observed coplanar growth for mode-mixities $\Phi$ between $45^{\circ}$ and $76^{\circ}$, see Figure 5 .

For a mode-mixity of $76^{\circ}$ they found that the crack growth rate is the sum of each contribution. However, for higher mode-mixities they found a synergetic effect resulting in a faster growth compared to the simple sum of both contributions. This effect was also observed by Wong et al. [38,39] for a rail steel. Doquet and Pommier explained the different bifurcation behavior between their and Wong's results, who observed deflection to tensile dominated crack propagation at mode-mixities below $63^{\circ}$, by the different loading conditions in both tests. 


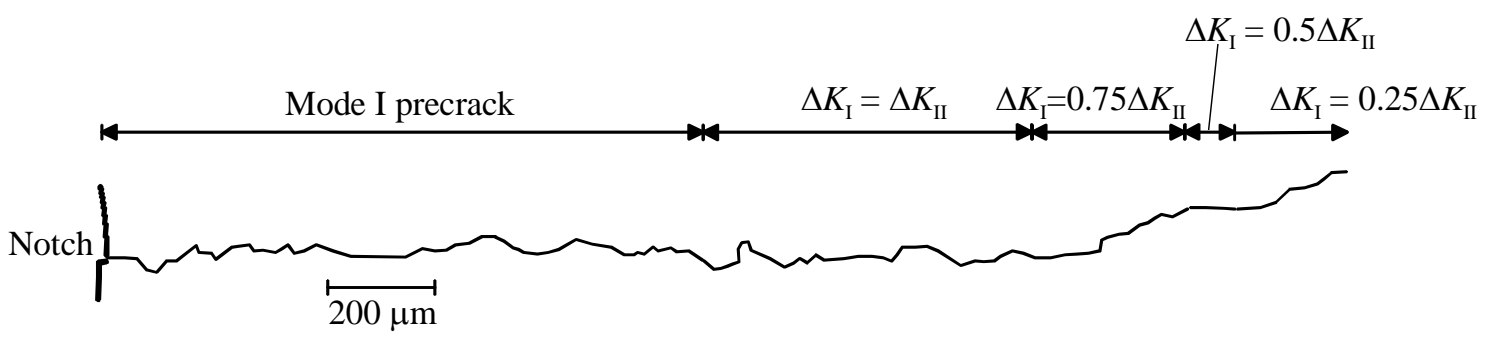

Figure 5. Crack path development in sequential mode I+II loading with $\Delta \mathrm{K}_{\mathrm{II}}=20 \mathrm{MPa} \mathrm{m}^{0.5}$ after Doquet and Pommier [37].

\section{Effect of superimposed static component on fatigue crack growth}

Another special case of non-proportional loading, which was often investigated in research, is the superposition of a static and a cyclic load component. Here, the following kinds of non-proportional loading can be distinguished:

1. Cyclic mode I loading and static mode II load

2. Cyclic mode II loading and static mode I load

3. Cyclic proportional loading and static mode I or II load

4. Cyclic mode I or II loading and static Mixed-mode load

Plank and Kuhn [40] studied the crack growth behavior under load cases (1), (2) and (4) on different aluminum alloys using compact tension shear specimen [41]. Within their studies they distinguish two modes of propagation, as shown in Fig. 6; a mode I controlled deviation named tensile mode and a coplanar mode II controlled crack growth named shear mode.


Mode II controlled
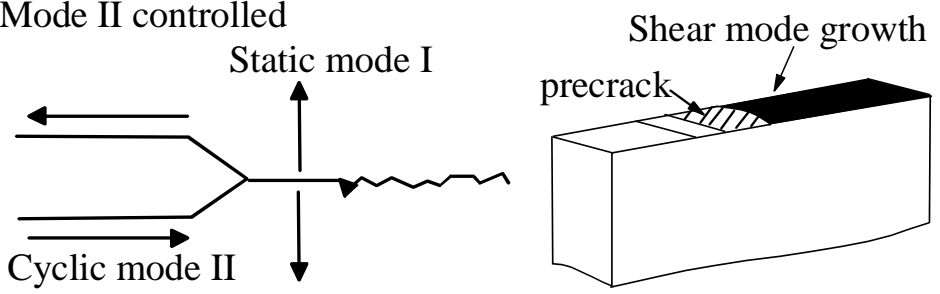

Figure 6. Different modes of stable crack growth after Plank and Kuhn [40]. 
They stated that stable shear mode crack growth can only be observed under cyclic mode II with superposed static mode I, while for cyclic mode I with superposed static mode II as well as for cyclic mixed-mode with superposed static mode I only stable tensile mode I crack growth is observed. Moreover, once the crack has turned into tensile mode it will not reverse to shear mode any more. Based on their experimental findings, they stated that two loading parameters and one material-specific parameter are decisive for the kind of crack propagation. For the initiation of shear mode crack growth, the effective range of the mode II stress intensity factor $\Delta \mathrm{K}_{\mathrm{II} \text {,eff }}$ must exceed a certain threshold value $\Delta \mathrm{K}_{\mathrm{II}, \mathrm{th}, \mathrm{sm}}$, which is material-specific. Furtermore, the $\Delta \mathrm{K}_{\mathrm{II}}$-value on the starter crack has to be larger than the mode I range $\Delta k_{1}$ an the infinitesimally short kink crack's tip. They also found $\Delta \mathrm{K}_{\mathrm{II}, \text { th,sm }}$ to be indirectly proportional to the average grain size.

Concerning the crack growth rates they found that under cyclic mode II a static mode I load leads to a significant increase in crack growth rate, because of the reduction of crack face contact. This result is confirmed by several other researchers, e.g. $[42,43,44,45]$. Moreover, at identical cyclic stress intensity factors, the crack growth rate is higher, if the crack is growing in shear mode than in tensile mode, what would be in accordance with Eq. (1). The introduction of a static mode II component on cyclic mode I loading leads to a decreasing crack growth rate and therefore to longer fatigue lives. Plank and Kuhn [40] explained this behaviour by increasing friction between the two crack faces.

\section{Effect of phase shift on fatigue crack growth}

A case of non-proportional loading, which has become much attention, is the out-ofphase loading. Especially the $90^{\circ}$ out-of-phase loading shows significant differences compared to the proportional loading. In Table 1 a comparison of fatigue lives under proportional and non-proportional loading is presented.

Referring to the results of the publications cited in Table 1, a phase shift from inphase loading to out-of phase loading leads to a increase in fatigue life, if the test are performed in a stress or load controlled condition. This increase is caused by a smaller increase in local deformations (plastic ratcheting) [9]. In contrast to this, under strain controlled test, the fatigue life decreases under out-of-phase loading compared to inphase loading. However, the material also plays an important role. What was said above holds for ductile materials wheras for semi-ductile materials a life reduction in straincontrolled condition could not be observed. The total life discussed here is the sum of the life to inititate a crack of technical size and subsequent fatigue crack growth. Whether or not these general statements on the total life can be transformed unaltered to the crack growth life alone has not yet been investigated. One aspect of this practically relevant distinction is that the fatigue cracks have to initiated in the test specimens applying the same load sequence as it is used in the crack growth investigation. In these cases, the academic abrupt initial mode changes hardly appear. A variety of such experimental results have been published by Brüning et al. [59,60,61]. In these experiments on thin-walled tubes under non-proportional tension and torsion, the wall 
thicknes increased considerably from the smallest net cross-section towards the clamping region due to shouldering. This mild notch effect enforced the fatigue crack to search its path in the region of small cross section, thus increasing the mode II contribution by torsion compared to a tube specimen with constant wall thickness. A seventh influence parameter - the component's geometry in general - has therefore been identified of affecting the non-proportional (and the proportional) mixed-mode fatigue crack growth.

Table 1. Comparison of fatigue lives under porportional and non-proportional loading (mainly after [46])

\begin{tabular}{|l|l|l|l|l|}
\hline Material & $\begin{array}{l}|c| \\
\text { for }\end{array}$ & $N_{90^{\circ}} / N_{0^{\circ}}$ \\
$\sigma_{\mathrm{a}}=$ const. & $N_{0^{\circ}}$, & $\begin{array}{l}\text { control } \\
\text { for } \\
\varepsilon_{\mathrm{a}}=\text { const. }\end{array}$ & $\begin{array}{l}\text { Reference } \\
\text { test }\end{array}$ \\
\hline Steel & 0.1 & - & $\sigma_{\mathrm{a}}$ & \\
\hline S460N & $10 \ldots 20$ & $0.21 \ldots 0.28$ & $\varepsilon_{\mathrm{a}}$ & Tipton [47] \\
\hline S460N & $2 \ldots 3$ & 0.3 & $\sigma_{\mathrm{a}}, \varepsilon_{\mathrm{a}}$ & Soffmeyer [48] \\
\hline CK45 & 0.4 & - & $\sigma_{\mathrm{a}}, \varepsilon_{\mathrm{a}}$ & Sonsino [50] \\
\hline SAE 1045 & 5 & 0.6 & $\sigma_{\mathrm{a}}, \varepsilon_{\mathrm{a}}$ & Pan [51] \\
\hline 25 CrMo4 & 0.6 & - & $\sigma_{\mathrm{a}}$ & Grün [52] \\
\hline 30 CrNiMo8 & 1.1 & 0.4 & $\sigma_{\mathrm{a}}, \varepsilon_{\mathrm{a}}$ & Sonsino [49] \\
\hline X6CrNiNb18-10 & - & $0.54 \ldots 1.4(\mathrm{LCF})$ & $\varepsilon_{\mathrm{a}}$ & Hoffmeyer [48] \\
\hline X6CrNiTi18-10 & 3.8 & 0.5 & $\sigma_{\mathrm{a}}, \varepsilon_{\mathrm{a}}$ & Hug [53] \\
\hline X10CrNiTi18-9 & 1.1 & 0.5 & $\sigma_{\mathrm{a}}, \varepsilon_{\mathrm{a}}$ & Sonsino [49] \\
\hline AlMg4.5Mn & 1 & $0.77 \ldots 0.9$ & $\varepsilon_{\mathrm{a}}$ & Hoffmeyer [48] \\
\hline 6061 Al T6 & - & 0.2 & $\varepsilon_{\mathrm{a}}$ & Xia [54] \\
\hline AlMgSi1 & - & 0.5 & $\varepsilon_{\mathrm{a}}$ & Ahmadi [55] \\
\hline AZ91 & - & $3 \ldots 4$ & $\varepsilon_{\mathrm{a}}$ & Renner [56] \\
\hline Ti-6Al-4V & - & 0.1 & $\varepsilon_{\mathrm{a}}$ & Nakamura [57] \\
\hline 1045 & - & $0.17 \ldots 2.81$ & $\varepsilon_{\mathrm{a}}$ & Fatemi [58] \\
\hline
\end{tabular}

\section{CONCLUSION}

A lack of tailored, validated and accepted mixed-mode hypotheses for application with especially non-proportional crack tip conditions must be stated. Specifying simply the sum of crack growth rated from each mode contribution as suggested by Doquet and Pommier [37] as well as Döring [46] is certainly not the final end of the development. A way out of purely empirical descriptions of experimental finding for special loading situations might be pointed by a rather unknown suggestion published by Hertel et al. [62]. The $\Delta J$-integral at a crack tip under non-proportional mixed mode loading remains - despite sound expectations - a fairly path independent quantity. The path 
independence - if validated for more cyclic load conditions - would suggest its application as crack driving force.

\section{REFERENCES}

1. Erdogan, F., Sih, G.C. (1963) J. Basic Engineering 85D, 519-527.

2. Shih, C.F. (1974). In: Fracture Analysis, pp. 187-210, Paris, P.C. and Irwin, G.R. (Eds.), ASTM STP 560, Philadelphia.

3. Sih, G.C. (1974) Int. J. Fracture 10, 305-321.

4. Hussain, M.A., Pu, S.L. and Underwood, J.H. (1974). In: Fracture Analysis, pp. 228, Paris, P.C. and Irwin, G.R. (Eds.) ASTM STP 560, Philadelphia.

5. Maccagno, T.M., Knott, J.F. (1992) Engng. Frac. Mech. 41, 805-820.

6. Hallback, N., Nilsson, F. (1994) J. Mech. Phys. Solids 42 1345-1374.

7. Qian, J., Fatemi, A. (1996) Engng. Frac. Mech. 55, 969-990.

8. Richard, H.A., Fulland, M. and Sander, M. (2005) Fatigue Fract. Engng Mater. Struct. 28, 3-12.

9. Sonsino, C.M. (2001) Int. J. Fatigue 23, 159-167.

10. Highsmith Jr., S. (2009). PhD Thesis, Georgia Institute of Technology, USA.

11. Iida, S., Kobayashi, A.S. (1969) ) J. Basic Engineering 91D, 764-769.

12. Roberts, R., Kibler, J.J. (1971) ) J. Basic Engineering 93D, 671-680.

13. Gao, H., Brown, M.W. and Miller, K.J. (1982) ) Fatigue Engng Mater. Struct. 5, 117.

14. Liu, H.W. (1985) Fatigue Fract. Engng Mater. Struct. 8, 295-313.

15. Bold, P.E., Brown, M.W. and Allen, R.J. (1992) Fatigue Fract. Engng Mater. Struct. 15, 965-977.

16. Hourlier, F., D’Hondt, H., Truchon, M. and Pineau, A. (1985) In: Multiaxial Fatigue, pp. 228-248, ASTM STP 853, Philadelphia.

17. Hourlier, F., Pineau, A. (1981) In: 5th Int. Conf. Fracture, pp. 1833-1840, Francois, D., Bathias, C. and Bilby, B.A. (Eds.), Pergamon Press, Oxford.

18. Smith, M.C., Smith, R.A. (1988) In: Basic Questions of Fatigue, pp. 260-280, ASTM STP 924, Fong, J.T., Fields, R.J. (Eds.), Philadelphia.

19. Bogdanski, S., Stupnicki, J., Brown, M.W. and Cannon, D.F. (1997) In: Multiaxial Fatigue and Fracture, pp. 235-248, Macha, E., Bedkowski, W. and Lagoda, T. (Eds.), Elsevier, Oxford.

20. Miller, K.J., Brown, M.W. and Yates, J.R. (1999) In: Proc. Symp. Mixed-Mode Crack Behavior, pp. 229-257, ASTM STP 1359, Philadelphia.

21. Desimone, H., Beretta, S. (2006) Int. J. Fatigue 28, pp. 635-642.

22. Otsuka, A., Mori, K., Ohshima, T. and Tsuyama, S. (1981) In: 5th Int. Conf. Fracture, pp. 1851-1859, Francois, D., Bathias, C. and Bilby, B.A. (Eds.), Pergamon Press, Oxford.

23. Prasad, N.N.V., Aliabadi, M.H. and Rooke, D.P. (1996) Int. J. Fatigue 18, pp. 349361. 
24. Tanaka, K., Akinawa, Y., Kato, T. and Mikuriya, T. (2005) Fatigue Fract. Engng Mater. Struct. 28, 73-82.

25. Spievak, L.E., Wawrzynek, P.A., Ingraffea, A.R. and Lewicki, D.G. (2001) Engng. Frac. Mech. 68, 53-76.

26. Yu, X., Abel, A. (2000) In: Proc. Int. Conf. Offshore Polar Engng. pp. 23-28, Int. Soc. Offshore and Polar Engineers, Golden.

27. Schijve, J. (1960). Report MP-195, National Aerospace Lab.

28. Hudson, C.M., Hardrath, H.F. (1961). NASA TN-D-960.

29. Nayeb-Hashemi, H., Taslim, M.E. (1987) Engng. Frac. Mech. 26, 789-807.

30. Gao, H., Upul, S.F. (1996) Fatigue Fract. Engng Mater. Struct. 19, 1197-1206.

31. Srinivas, V., Vasudevan, P. (1993) Int. J. Vessels Piping 56, 409-417.

32. Sander, M., Richard, H.A. (2003) Int. J. Fatigue 25, 999-1005.

33. Dahlin, P., Olsson, M. (2004) Int. J. Fatigue 26, 1083-1093.

34. Dahlin, P., Olsson, M. (2005) Report 399, KTH Solid Mechanics, Stockholm, Sweden.

35. Dahlin, P. (2005) PhD Thesis, KTH Solid Mechanics, Stockholm, Sweden.

36. Dahlin, P., Olsson, M. (2008) Int. J. Fatigue 30, 931-941.

37. Doquet, V., Pommier, S. (2004) Fatigue Frac. Engng Mater. Struct. 27, 1051-1060.

38. Wong, S.L., Bold, P.E., Brown, M.W., Allen, R.J. (1996) Wear 191, 45-53.

39. Wong, S.L., Bold, P.E., Brown, M.W., Allen, R.J. (2000) Fatigue Fract. Engng Mater. Struct. 23, 667-674.

40. Plank, R., Kuhn, G. (1999) Engng Fracture Mech. 62, 203-229.

41. Richard, H.A. (1985). VDI Forschungsheft 631, VDI Verlag, Düsseldorf.

42. Wang, X., Gao, Z., Qiu, B., Wang, L., Jiang, Y. (2011) Chinese J. Mech. Engng 24, 195-201.

43. Kaufmann, R.P., Bonnen, J.J.F., Topper, T.H. (2002). In: Proceedings of the 8th International Fatigue Congress, pp. 307-314, Elsevier.

44. Kaufmann, R.P., Topper, T.H. (2001). In: Proseedings of the 6th International Conference on Biaxial/Multiaxial Fatigue and Fracture, pp. 203-212, de Freitas, M. (Ed.), ESIS.

45. Zhang, W., Akid, R. (1997) Fatigue Fract. Engng Mater. Struct. 20, 547-557.

46. Döring, R. (2006) PhD Thesis, TU Darmstadt, Germany.

47. Tipton, S.M., Nelson, D.V. (1997) Int. J. Fatigue 19, 503-516.

48. Hoffmeyer, J. (2005) PdD Thesis, TU Darmstadt, Germany.

49. Sonsino, C.M. (1995) Materialwissenschaft und Werkstofftechnik 26, 425-441.

50. Sonsino, C.M. (2001) Fatigue Fract. Engng Mater. Struct. 24, 309-327.

51. Pan, W.F., Hung, C.Y., Chen, L.L. (1999) Int. J. Fatigue 21, 3-10.

52. Grün, P., Troost, A., Akin, O., Klubberg, F. (1991) Materialwissenschaft und Werkstofftechnik 22, 73-80.

53. Hug, J. (1994) PhD Thesis, TU Clausthal-Zellerfeld, Germany.

54. Xia, Z., Ellyin, F. (1998) Int. J. Fatigue 20, 51-56.

55. Ahmadi, A., Zenner, H., Düwel, V., Schram, A. (2002) Materialwissenschaft und Werkstofftechnik 33, 265-279.

56. Renner, F. (2004). PhD Thesis, TU Clausthal-Zellerfeld, Germany. 
57. Nakamura, H., Takanashi, M., Itoh, T., Wu, M., Shimizu, Y. (2011) Int. J. Fatigue 33, 842-848.

58. Fatemi, A., Socie, D.F. (1988) Fatigue Fract. Engng Mater. Struct. 11,149-165.

59. Brüning, J. (2008) PhD Thesis, TU Darmstadt, Germany.

60. Zerres, P., Brüning, J. and Vormwald, M. (2010) Engng Fracture Mech. 77, 18221834.

61. Zerres, P., Brüning, J. and Vormwald, M. (2011) Mat. Testing 03/2011, 109-117.

62. Hertel, O., Döring, R. and Vormwald, M. (2004) In: Proc. 7th Int. Conf. of Biaxial/ Multiaxial Fatigue and Fracture, pp. 513-518, DVM, Berlin. 